\begin{tabular}{|c|l|}
\hline Title & Rapid reduction of titanium dioxide nano-particles by reduction with a calcium reductant \\
\hline Author(s) & $\begin{array}{l}\text { Kikuchi, Tatsuy a; Y oshida, Masumi; Matsuura, Shiki; Natsui, Shungo; T suji, Etsuji; Habazaki, Hiroki; Suzuki, } \\
\text { Ryosuke O. }\end{array}$ \\
\hline Citation & $\begin{array}{l}\text { Journal of Physics and Chemistry of Solids, 75(9), 1041-1048 } \\
\text { https://doi.org/10.1016/.jpcs.2014.04.016 }\end{array}$ \\
\hline Issue Date & 201409 \\
\hline Doc URL & http://hdl.handle.net/2115/56408 \\
\hline Type & article (author version) \\
\hline File Information & NanoT i02-2.pdf \\
\hline
\end{tabular}

Instructions for use 


\section{Rapid reduction of titanium dioxide nano-particles by reduction with a calcium reductant}

Tatsuya Kikuchi ${ }^{a}{ }^{*}$, Masumi Yoshida ${ }^{a}$, Shiki Matsuura ${ }^{b}$, Shungo Natsui ${ }^{a}$, Etsuji Tsuji ${ }^{a}$, Hiroki Habazaki ${ }^{\mathrm{a}}$, and Ryosuke O. Suzuki ${ }^{\mathrm{a}}$

${ }^{a}$ Faculty of Engineering, Hokkaido University

N13-W8, Kita-ku, Sapporo, Hokkaido, 060-8628, Japan

${ }^{\mathrm{b}}$ Graduate School of Chemical Science and Engineering, Hokkaido University

N13-W8, Kita-ku, Sapporo, Hokkaido, 060-8628, Japan

*Corresponding author: Tatsuya Kikuchi

TEL: +81-11-706-6340

FAX: +81-11-706-6342

E-mail: kiku@eng.hokudai.ac.jp 


\begin{abstract}
Micro-, submicron-, and nano-scale titanium dioxide particles were reduced by reduction with a metallic calcium reductant in calcium chloride molten salt at $1173 \mathrm{~K}$, and the reduction mechanism of the oxides by the calcium reductant was explored. These oxide particles, metallic calcium as a reducing agent, and calcium chloride as a molten salt were placed in a titanium crucible and heated under an argon atmosphere. Titanium dioxide was reduced to metallic titanium through a calcium titanate and lower titanium oxide, and the materials were sintered together to form a micro-porous titanium structure in molten salt at high temperature. The reduction rate of titanium dioxide was observed to increase with decreasing particle size; accordingly, the residual oxygen content in the reduced titanium decreases. The obtained micro-porous titanium appeared dark gray in color because of its low surface reflection. Micro-porous metallic titanium with a low oxygen content $(0.42 \mathrm{wt} \%)$ and a large surface area $\left(1.794 \mathrm{~m}^{2} \mathrm{~g}^{-1}\right)$ can be successfully obtained by reduction under optimal conditions.
\end{abstract}

Key words: Titanium, Calcium, Calciothermic reduction, Nano-particles, Electrolytic capacitor 


\section{Introduction}

Metallic calcium can easily reduce a large number of metal oxides directly to metals because calcium has a strong reducing ability. The reduction of metal oxides with a calcium reductant in calcium chloride molten salt at high temperature, well known as the calciothermic reaction, has long been widely investigated by many researchers. During oxide reduction, calcium chloride molten salt acts as a suitable solvent and has a high solubility for calcium and calcium oxide as a byproduct formed by reduction. Metallic titanium [1], zirconium [2], hafnium [3], niobium [4], tantalum [4], vanadium-titanium [5], titanium-aluminum-vanadium [6], titanium-chromium [7-9], samarium-iron [10], and niobium aluminide [11] are formed via reduction of these oxides with a calcium reductant in calcium chloride molten salt. The residual oxygen in the reduced metal decreases continuously by deoxidation with a calcium reductant [4]. Pure metals, alloys, and intermetallic compounds with a lower residual oxygen content can be successfully fabricated by a one-step reduction technique. Reduction with a calcium reductant is a simpler technique for the production of these metals without complicated processes such as the Kroll process, although reduction is a batch-type production method.

In recent years, a method for the successive reduction of metal oxides was developed by electrolysis in calcium chloride and calcium oxide mixture molten salts. Ono and Suzuki reported that calcium oxide in molten calcium chloride becomes the reductant source for the reduction of metal oxides during constant-voltage electrolysis [12]. For example, metallic calcium formed electrochemically at a cathode reacts with metal oxides, and reduced metals with a low residual oxygen content can be formed (OS (Ono and Suzuki) Kyoto process). Metallic titanium [13-15], niobium [16], nickel [17], and other alloys and intermetallic compounds $[18,19]$ can be formed via the OS process. In addition, the electrochemical decomposition of carbon dioxide gas by an advanced OS process using a solid electrolyte anode has been reported [20, 21]. Fray, Farthing, and Chen investigated the cathodic deoxidation of metal oxides in calcium chloride and calcium oxide mixture molten salts and reported the production of metallic titanium [22-26], iron [27], chromium [28], zirconium [29], hafnium [30], tantalum [31], and other alloys [32-34] through the FFC (Fray, Farthing, and Chen) Cambridge process. Several other research groups have also investigated the successive reduction of metal oxides based on electrolysis in molten calcium chloride [33-41].

Very recently, the authors have investigated the fabrication of a metallic titanium and zirconium micro-porous alloy by reduction with a calcium reductant in calcium chloride molten salt for novel electrolytic capacitor applications [44]. It is known that defect-free, high-capacitance composite anodic oxide films can be formed on substrates by anodizing a Ti-62.5 at\% $\mathrm{Zr}$ alloy [45-51]. Therefore, a simple fabrication process for creating a micro-porous Ti-Zr alloy with large surface area must be developed to create novel Ti-Zr capacitors. In our previous investigation, a metallic Ti-Zr alloy was formed by reduction in the presence of excess calcium reductant and possessed a micro-porous 
morphology because of the sintering of each reduced oxide particle during the reduction. The micro-porous alloy, which had a low oxygen content $(0.20 \mathrm{wt} \%)$ and a large surface area $\left(0.55 \mathrm{~m}^{2} \mathrm{~g}^{-1}\right)$, was successfully obtained under optimal reduction conditions. In this investigation, titanium and zirconium oxide micro-particles measuring a few $\mu \mathrm{m}$ in diameter were used as the starting materials for reduction. Reduction using smaller oxides, including submicron- and nano-particles, may yield the following advantages for electrolytic capacitor applications: a) an increase in the reduction rate, b) an increase in the surface area of the reduced metal micro-porous structure, c) a decrease in the residual oxygen content in the reduced alloy, and d) the formation of an alloy with uniform chemical composition. Conversely, the residual oxygen content may increase with decreasing the particle size because of re-oxidation of the titanium surface during the washing step. Therefore, the residual oxygen content will be a compromise between these advantages and disadvantages.

In the present investigation, we studied the effect of particle size on the reduction of titanium dioxide to metallic titanium through reduction with a calcium reductant in calcium chloride molten salt. In the process, titanium dioxide micro-, submicron-, and nano-particles as the starting oxide materials were reduced by calcium in molten salt at high temperature. The reduction of submicron- and nano-particles was expected to rapidly yield metallic titanium micro- or nano-porous structures with large surface area. The reduction rate, residual oxygen content, and obtained metallic titanium morphology were investigated from the viewpoint of novel electrolytic capacitor applications, and the reduction mechanism of the calcium reductant was also examined.

\section{Experimental}

\subsection{Starting materials}

Three types of commercially available titanium oxide powders were used as the starting materials: micro-particles $(99.9 \mathrm{wt} \%$, average diameter of particles, $\mathrm{D}=2.0 \mu \mathrm{m}$, determined by scanning electron microscopy (SEM), Furuuchi Chemical, Japan), submicron-particles $(99.99 \mathrm{wt} \%, \mathrm{D}=90 \mathrm{~nm}$, identified by SEM, Ishihara Sangyo, Japan), and nano-particles ( $99.986 \mathrm{wt} \%, \mathrm{D}=13 \mathrm{~nm}$, identified by BET method, Tecnan, Spain). The oxides and anhydrous calcium chloride (99.0 wt $\%$, Kojundo Chemical Laboratory, Japan), which was used as a molten salt, were dried in a vacuum oven at $473 \mathrm{~K}$ for several hours. Metallic calcium lumps (99.0 wt\%, Hitachi Alloy, Japan) were also used as a reductant for the reduction of titanium oxides in molten salt.

\subsection{Reduction of titanium oxide}

Oxide powder $(2.0 \mathrm{~g})$, calcium chloride $(100 \mathrm{~g})$, and metallic calcium $(3.0 \mathrm{~g})$ were placed in a titanium crucible (SH-632B-Ti, Sugiyama-Gen, Japan). The crucible was set in a SUS316L stainless steel vessel, and the vessel was covered by two large SUS316L plates and screws. The vessel was placed in a reaction chamber (SUS316L), and the chamber was then slowly heated to $873 \mathrm{~K}$ within $30 \mathrm{~min}$ under vacuum conditions. The 
temperature was held at $873 \mathrm{~K}$ for $10 \mathrm{~min}$ to remove residual moisture from the materials. After the removal of moisture, argon gas $(101.3 \mathrm{kPa})$ was introduced into the chamber. The temperature was then gradually increased to $1173 \mathrm{~K}$ within $10 \mathrm{~min}$ and held for an additional 15-360 min for the reduction of titanium oxides by the calcium reductant (melting point, $\left.T_{m}=1112 \mathrm{~K}\right)$ in the calcium chloride molten salt $\left(\mathrm{T}_{\mathrm{m}}=1045\right.$ $\mathrm{K})$. The reduction of titanium oxides can be expressed by the following reaction:

$$
\mathrm{TiO}_{2}+2 \mathrm{Ca}=\mathrm{Ti}+2 \mathrm{Ca}^{2+}+\mathrm{O}^{2-} \quad \text { in molten } \mathrm{CaCl}_{2}
$$

The theoretical amount of metallic calcium required for the complete reduction of titanium oxides was defined as $\mathrm{e}=100 \%$, and the quantities of metallic calcium used as the reductant were adjusted to $\mathrm{e}=150 \%$ (50\% excess calcium, $3.0 \mathrm{~g}$ ) because of the small amount of liquid calcium that evaporated from the surface of the molten salt. In a previous investigation, we observed that excess calcium reductant caused the complete reduction of titanium and zirconium oxides. The details of the reduction setup used in the present investigation have been described elsewhere [44].

After reduction, the reaction chamber was cooled to room temperature for $12 \mathrm{~h}$. The titanium crucible was removed from the vessel and then washed with water to remove the solidified calcium chloride salt. The reduced materials obtained from the crucible bottom were washed again with acetic acid, ethanol, and acetone to remove residual impurities. Finally, the materials were dried and stored in a vacuum desiccator.

The phase composition of the obtained materials was identified by X-ray diffraction analysis (XRD, XpertPro, Phillips). The residual oxygen content in the materials was quantitatively analyzed by an inert gas fusion-infrared absorption method using an oxygen/nitrogen analyzer (TC600, LECO). Structural changes in the materials caused by reduction were examined by SEM (Miniscope TM-1000, Hitachi). The specific surface area of the specimens was determined by the Brunauer, Emmett, and Teller method (BET, BELSORP-mini, BEL Japan).

\section{Results and discussion}

Figure 1 shows X-ray diffraction patterns of the $\mathrm{TiO}_{2}$ a) micro-, b) submicron-, and c) nano-particles, which were prepared as the starting materials for reduction. In the case of the micro-particles (Fig. 1a), strong diffraction peaks from the rutile phase and weak peaks from the anatase phase were detected. Specifically, the $\mathrm{TiO}_{2}$ micro-particles were identified as rutile micro-particles accompanied by a small amount of anatase micro-particles. In the submicron-particles (Fig. 1b), similar peaks for the rutile and anatase phases were observed, and the full width at half-maximum (FWHM) of each diffraction peak increased slightly relative to that of the micro-particles due to the decrease in the average diameter of the particles $(\mathrm{D}=2.0 \mu \mathrm{m}$ and $90 \mathrm{~nm}$, respectively). For the nano-particles (Fig. 1c), the $\mathrm{TiO}_{2}$ particles were identified as anatase nano-particles accompanied by a small amount of rutile nano-particles. The XRD pattern showed broad peaks at each angle, indicating nanometer-scale particles. The average size of the $\mathrm{TiO}_{2}$ nano-particles can be calculated by the Scherrer equation [52]: 


$$
\mathrm{D}=\mathrm{K} \lambda / \beta \cos \theta
$$

where $\mathrm{K}$ is a constant related to the crystallite shape $(\mathrm{K}=0.9), \lambda$ is the wavelength $(\lambda=$ $0.154 \mathrm{~nm}), \beta$ is the FWHM value, and $\theta$ is the Bragg angle. By substituting $0.3897^{\circ}$ for $\beta$ at $2 \theta=25.29$, the $\mathrm{D}$ value of the anatase $\mathrm{TiO}_{2}$ nano-particles is estimated to be 20.9 $\mathrm{nm}$. This nano-particle size calculated by the Scherrer equation is considered to be similar to that obtained by the BET method $(\mathrm{D}=13 \mathrm{~nm})$.

The reduction of $\mathrm{TiO}_{2}$ micro-, submicron-, and nano-particles with a calcium reductant in $\mathrm{CaCl}_{2}$ molten salt at $1173 \mathrm{~K}$ was performed to clarify the details of the reduction behavior of the particles. The X-ray diffraction patterns obtained from the oxide particles after reduction for $15 \mathrm{~min}$ are shown in Fig. 2. Calcium titanate $\left(\mathrm{CaTiO}_{3}\right)$ and a lower titanium oxide $\left(\mathrm{Ti}_{2} \mathrm{O}\right)$ were obtained as shown in Fig. 2a when $\mathrm{TiO}_{2}$ micro-particles were used as the starting materials, although metallic titanium was also obtained. Indeed, the $\mathrm{TiO}_{2}$ micro-particles were not reduced completely after 15 min of reduction. Similarly, metallic titanium containing a small amount of $\mathrm{CaTiO}_{3}$ was obtained by the incomplete reduction of the $\mathrm{TiO}_{2}$ submicron-particles (Fig. 2b). In contrast, the complete reduction of the $\mathrm{TiO}_{2}$ nano-particles was observed, and it was clear that pure metallic titanium could be produced using nano-particles (Fig. 2c). From these investigations, it was observed that using fine nano-particles as the starting materials in the reduction caused the complete reduction of titanium oxide within a short reduction period of $15 \mathrm{~min}$.

Figure 3 shows the X-ray diffraction patterns obtained from a) $\mathrm{TiO}_{2}$ micro-, b) submicron-, and c) nano-particles after reduction for $30 \mathrm{~min}$. The diffraction patterns show no peak associated with titanium oxide, calcium titanate, or lower titanium oxide over the entire particle size range; the patterns also indicate that a pure metallic titanium could be successfully formed by $30 \mathrm{~min}$ of reduction. Therefore, the $\mathrm{CaTiO}_{3}$ and $\mathrm{Ti}_{2} \mathrm{O}$ produced by $15 \mathrm{~min}$ of reduction (Figs. 2a and $2 \mathrm{~b}$ ) were completely reduced by an additional 15 min of reduction (Figs. $3 a$ and $3 b$ ).

The reduction of titanium oxide using a calcium reductant in calcium chloride molten salt at high temperature can be represented by the following electrochemical reactions:

$$
\begin{gathered}
\mathrm{TiO}_{2}+4 \mathrm{e}^{-}=\mathrm{Ti}+2 \mathrm{O}^{2-} \quad \text { (Cathodic reaction) } \\
2 \mathrm{Ca}=2 \mathrm{Ca}^{2+}+4 \mathrm{e}^{-} \quad \text { (Anodic reaction) }
\end{gathered}
$$

and the overall reaction is described by reaction (1). During reduction in $\mathrm{CaCl}_{2}$ at 1173 $\mathrm{K}$, molten metallic calcium (melting point: $1112 \mathrm{~K}$ ) may have floated to the surface of the molten $\mathrm{CaCl}_{2}$ because the density of the former is lower than that of the latter. However, metallic calcium is dissolved in molten $\mathrm{CaCl}_{2}$ because the solubility of the metallic calcium in molten $\mathrm{CaCl}_{2}$ at $1173 \mathrm{~K}$ is approximately $3.9 \mathrm{~mol} \%$. Namely, metallic calcium $\left(\mathrm{Ca}^{0}\right)$-calcium chloride molten salt $\left(\mathrm{Ca}^{2+}\right.$ and $\left.\mathrm{Cl}^{-}\right)$mixtures were formed at $1173 \mathrm{~K}$. In addition, approximately $20 \mathrm{~mol} \%$ calcium oxide $(\mathrm{CaO})$ can be dissolved in molten $\mathrm{CaCl}_{2}$. Therefore, metallic calcium can easily react with titanium oxide particles, and byproduct $\mathrm{CaO}$ formed by the reduction is dissolved rapidly in 
molten $\mathrm{CaCl}_{2}$, as described by equation (1). Here, metallic calcium $\left(\mathrm{Ca}^{0}\right)$-dissolved calcium oxide $\left(\mathrm{Ca}^{2+}\right.$ and $\left.\mathrm{O}^{2-}\right)$-calcium chloride molten salt $\left(\mathrm{Ca}^{2+}\right.$ and $\left.\mathrm{Cl}^{-}\right)$mixtures were formed after the reduction of titanium dioxide.

During reduction, titanium oxides are reduced to their metallic phase through lower titanium oxides, which are called Magneli phases, such as $\mathrm{Ti}_{2} \mathrm{O}_{3}, \mathrm{TiO}, \mathrm{Ti}_{2} \mathrm{O}, \mathrm{Ti}_{3} \mathrm{O}$, and $\mathrm{Ti}_{6} \mathrm{O}[53,54]$. Accordingly, metallic titanium containing lower titanium oxides is formed by reduction under incomplete reduction conditions, as illustrated in Fig. 2a. In addition, some of the byproduct $\mathrm{CaO}$ reacts with the residual, unreacted titanium oxide particles by the following chemical reaction:

$$
\mathrm{TiO}_{2}+\mathrm{CaO}=\mathrm{CaTiO}_{3}
$$

Therefore, $\mathrm{CaTiO}_{3}$ was also observed by reduction under incomplete reduction conditions, as shown in Figs. 2a and 2b. Reduction over longer periods causes the complete reduction of $\mathrm{CaTiO}_{3}$ and $\mathrm{Ti}_{2} \mathrm{O}$ to metallic titanium, as illustrated in Fig. 3:

$$
\mathrm{CaTiO}_{3}+2 \mathrm{Ca}=\mathrm{Ti}+3 \mathrm{Ca}^{2+}+3 \mathrm{O}^{2-}(3 \mathrm{CaO})
$$

To summarize the above-described reduction mechanism, titanium oxides can be reduced to metallic titanium through Magneli phases and calcium titanate during reduction with a calcium reductant. By comparing Figs. 2 and 3, it is clear that the reduction rate of titanium oxide increases with the decrease in the average particle diameter: nano- $>$ submicron- $>$ micro-particles. This is due to the increase of the surface area of titanium dioxides. Namely, the reduction rate increases with the reaction surface area of electrochemical reduction.

Figure 4 shows the residual oxygen content, $\mathrm{C}_{\mathrm{o}}$, in the reduced micro-, submicron-, and nano-particles at different reduction times, t (Fig. 4a: 60 min, 4b: 360 min), with a calcium reductant in $\mathrm{CaCl}_{2}$ molten salt at $1173 \mathrm{~K}$. The $\mathrm{C}_{\mathrm{o}}$ of each titanium dioxide starting material can be defined as $40.1 \mathrm{wt} \%$. In the case of reduction using $\mathrm{TiO}_{2}$ micro-particles, the oxygen content decreased rapidly with the reduction time during the initial reduction period for $\mathrm{t}=60 \mathrm{~min}$ (Fig. 4a). After $15 \mathrm{~min}$ of reduction, the content showed a relatively large value of $11.7 \mathrm{wt} \%$ because of the formation of calcium titanate and lower titanium oxide by the incomplete reduction described in Fig. 2a. Reduction for a longer period of 30 min caused the formation of metallic titanium (Fig. 3a), although $1.74 \mathrm{wt} \%$ of the oxygen content still remained in the metallic titanium because the oxygen was dissolved in the titanium lattice interstitially and formed a Ti-O solid solution. Reduction for $60 \mathrm{~min}$ resulted in additional deoxidation from the solid solution, and the oxygen content showed a small value of $0.56 \mathrm{wt} \%$. This decrease in oxygen content from the titanium solid solution suggests that the residual oxygen in the solid solution can also be removed by reduction with the dissolved calcium reductant. Comparing the reduction of submicron- and nano-particles with that of micro-particles, it is clear that the value of $\mathrm{C}_{\mathrm{o}}$ decreased with particle size at each reduction time. For example, the value of $\mathrm{C}_{\mathrm{o}}$ of micro-, submicron-, and nano-particles after $30 \mathrm{~min}$ of reduction were measured to be $1.74 \mathrm{wt} \%, 1.12 \mathrm{wt} \%$, and $0.96 \mathrm{wt} \%$, respectively. 
When the reduction time was over 60 min (Fig. 4b), the value of $\mathrm{C}_{\mathrm{o}}$ gradually decreased with increasing reduction time for each type of $\mathrm{TiO}_{2}$ particle and showed a small value of approximately $0.2 \mathrm{wt} \%$ (2000 ppm) after $360 \mathrm{~min}$. The residual oxygen content of the micro-particle after long-term reduction is approximately same as that of the submicron- and nano-particles, although the oxygen content decreases with particle size under short-term reduction due to its rapid electrochemical reaction. Namely, the oxygen content under all reduction conditions reaches a same minimum value after long-term reduction. A residual oxygen content of several thousand ppm is acceptable for electrolytic capacitor applications. In fact, an oxygen content of approximately 4000 ppm is allowed for tantalum electrolytic capacitors [55]. This small oxygen content can also be realized by the reduction of nano-particles over a short time of $60 \mathrm{~min}$ (Fig. 4a). In this study, the use of these smaller $\mathrm{TiO}_{2}$ particles resulted in rapid reduction in $\mathrm{CaCl}_{2}$ molten salt. This behavior was due to the large surface area of the $\mathrm{TiO}_{2}$ submicron- and nano-particles used for reduction with a calcium reductant.

Figure 5 shows the typical surface appearances of the reduced $\mathrm{TiO}_{2}$ nano-particles used for reduction after a) $60 \mathrm{~min}$ and b) $360 \mathrm{~min}$, the residual oxygen content data for which are shown in Fig. 4. Fig. 5a shows that metallic titanium particles measuring approximately a few hundred or tens of $\mu \mathrm{m}$ in diameter were formed after $60 \mathrm{~min}$ of reduction, and several large particles were also observed because these particles were sintered together. The particles appeared dark gray in color because of their lower surface reflection. The size of the obtained metallic titanium increased with the reduction time by sintering in molten salt at high temperature, and relatively large particles measuring approximately 1-2 $\mathrm{mm}$ in diameter were observed after $360 \mathrm{~min}$ of reduction (Fig. 5b). In addition, several particles showed a metallic luster after a long period of reduction, as indicated by yellow arrows. In this case, it is concluded that the metallic titanium possessed a flat surface due to excessive sintering.

Fig. 6a shows an SEM image of the surface of the titanium dioxide micro-particles used as starting materials for the reduction. It is observed that the micro-particles consisted of aggregates of spherical primary titanium oxide particles measuring 2-4 $\mu \mathrm{m}$. The micro-particles reduced with a calcium reductant in calcium chloride molten salt for $15 \mathrm{~min}$ are shown in Fig. 6b. Calcium titanate $\left(\mathrm{CaTiO}_{3}\right)$ particles with cubic microstructures (approximately 3-4 $\mu \mathrm{m}$ in diameter, perovskite structure) and many small particles of lower titanium oxide or metallic titanium (a few hundred $\mathrm{nm}$ in diameter), defined by EPMA analysis, can be observed in the figure. After 120 min of reduction (Fig. 6c), a micro-porous titanium structure composed of primary titanium particles measuring a few $\mu \mathrm{m}$ was obtained by sintering the titanium particles in calcium chloride molten salt at high temperature $(\mathrm{T}=1173 \mathrm{~K})$. The reduced titanium microstructure was sintered by submitting the particles to $360 \mathrm{~min}$ of further reduction, yielding a large titanium micro-porous structure (Fig. 6d). The Pilling-Bedworth ratio (P-B ratio) of titanium and its dioxide are 1.93 for anatase, 1.76 for rutile, and 2.4 for the amorphous phase [56], and the reduced titanium should shrink 
to approximately $50 \mathrm{vol} \%$ of its original size after complete reduction. However, the shrinkage of the titanium particles was not observed in Fig. 6a through 6d due to the sintering of the reduced titanium, although the lower titanium oxide and incompletely reduced titanium shrank as shown in Fig. 6b.

SEM images demonstrating changes in the surface morphology of submicronand nano-particles during reduction are shown in Fig. 7 and 8, respectively. In the case of submicron-particles (Fig. 7), a micro-porous structure composed of primary particles measuring a few hundred nm was obtained by reduction for $15 \mathrm{~min}$ (Fig. 7b), although the obtained materials possessed a relatively high residual oxygen content due to incomplete reduction (approximately $6 \mathrm{wt} \%$, Fig. 4). Further reduction caused the formation of metallic titanium (Fig. 3 and 4), and the particle size of the reduced micro-porous structure increased with the reduction time by sintering (Fig. $7 \mathrm{~b}$ though $7 \mathrm{~d})$. In the reduction of nano-particles, the reduced metallic titanium was also sintered by a long period of immersion in calcium chloride molten salt at high temperature (Figs. $8 \mathrm{~b}$ through $8 \mathrm{~d}$ ), and Fig. $8 \mathrm{~d}$ shows that the metallic titanium became a large lumped structure with small surface area.

Base on the SEM images of the reduced materials shown in Fig. 6 through Fig. 8, the microstructure morphology and corresponding surface area obtained by reduction with the calcium reductant is shown to strongly depend on the reduction time. These figures suggest that the surface area of the obtained micro-porous titanium decreases as the reduction time increases. Table 1 summarizes the metallic phase, residual oxygen content, and BET specific surface area of the reduced nano-particles formed by reduction for 60 and $360 \mathrm{~min}$. The starting $\mathrm{TiO}_{2}$ nano-particles possessed an extremely large surface area of $120.3 \mathrm{~m}^{2} \mathrm{~g}^{-1}$ and measured $13 \mathrm{~nm}$ in particle diameter. After reduction for $60 \mathrm{~min}$, the BET specific surface area of the reduced micro-porous titanium gradually decreased to $1.794 \mathrm{~m}^{2} \mathrm{~g}^{-1}$ due to the sintering of the reduced titanium particles. Further reduction for 360 min caused the surface area to decrease to $0.1554 \mathrm{~m}^{2}$ $\mathrm{g}^{-1}$, although the residual oxygen content showed the lowest value of $0.23 \mathrm{wt} \%$. A large decrease in the surface area caused by sintering during reduction is unacceptable for electrolytic capacitor applications, as described in the introduction section, because the capacitance of the electrolytic capacitor, $\mathrm{C}$, is proportional to the surface area of the reduced materials:

$$
\mathrm{C}=\varepsilon_{0} \varepsilon \mathrm{S} / \delta
$$

where $\varepsilon_{0}$ is the permittivity of free space, $\varepsilon$ is the specific dielectric constant of the anodic oxide film, $\mathrm{S}$ is the surface area of the electrode, and $\delta$ is the thickness of the oxide film. Therefore, metallic titanium reduced for 60 min may be suitable for electrolytic capacitor materials, even though this residual oxygen content is slightly higher than that of titanium obtained by reduction for $360 \mathrm{~min}$.

The reduction behaviors of the $\mathrm{TiO}_{2}$ micro- and nano-particles obtained by our experimental results are schematically described in Fig. 9. For $\mathrm{TiO}_{2}$ micro-particles (Fig. 9a), metallic titanium is reduced by reduction at a slow rate through a calcium titanate 
and lower titanium oxide and then sintered to form micro-porous titanium structures. Further sintering causes the formation of micro-porous titanium with a relatively large surface area; however, the residual oxygen content decreases with increasing reduction time. In contrast, $\mathrm{TiO}_{2}$ nano-particles are rapidly reduced under the same experimental conditions due to their large surface area for reaction sites (Fig. 9b). However, the residual oxygen content is still high due to the incomplete deoxidation of the reduced materials. Further reduction causes the oxygen content to decrease; however, the surface area decreases with increasing reduction time due to sintering, as observed for $\mathrm{TiO}_{2}$ micro-particles. The obtained micro-porous metallic titanium reduced from micro-, submicron-, and nano-particles possessed almost same morphology due to the long-term sintering. Therefore, we can conclude that the use of smaller oxide particles in reduction by a calcium reductant in molten salt causes rapid reduction and lower residual oxygen content in the reduced metal.

\section{Conclusions}

In this study, we demonstrated the reduction of titanium dioxide micro-, submicron-, and nano-particles by a calcium reductant in calcium chloride molten salt at $1173 \mathrm{~K}$, and the effects of the particle size and reduction time were investigated. Titanium dioxide is reduced to metallic titanium through a calcium titanate and lower titanium oxide by reduction, and the reduced titanium is sintered in molten salt at high temperature. The decrease in $\mathrm{TiO}_{2}$ particle size from that of micro-particles to that of nano-particles causes the reduction rate to increase and reduces the residual oxygen content. Micro-porous metallic titanium, which has a low oxygen content $(0.42 \mathrm{wt} \%)$ and a large surface area $\left(1.794 \mathrm{~m}^{2} \mathrm{~g}^{-1}\right)$, can be successfully obtained by nano-particle reduction under optimal reduction conditions. These findings could be adapted to produce a Ti-Zr micro-porous alloy for use in novel, high-capacitance electrolytic capacitors.

\section{Acknowledgments}

This research was conducted at Hokkaido University and was supported by the "Nanotechnology Platform" Program of the Ministry of Education, Culture, Sports, Science, and Technology (MEXT), Japan. This work was financially supported by the Japan Society for the Promotion of Science (JSPS) "KAKENHI" and by the Light Metal Educational Foundation, Japan.

\section{References}

1) R.O. Suzuki, K. Ono, K. Teranuma, Metall. Mater. Trans. B 34 (2003) 287-295.

2) A. M. Abdelkader, E. El-Kashif, ISIJ Int. 47 (2007) 25-31.

3) A. M. Abdelkader, A Daher, J. Alloys Compd. 469 (2009) 571-575.

4) M. Baba, Y. Ono, R.O. Suzuki, J. Phys. Chem. Solids, 66 (2005) 466-470.

5) R.O. Suzuki, K. Tatemoto, H. Kitagawa, J. Alloys Compd. 385 (2004) 173-180. 
6) B.S. Moorhouse, T. Reddyhoff, M. Ward-Close, M.P. Ryan, B.A. Shollock, Surf. Coat. Technol. 221 (2013) 214-221.

7) O. Bayat, A.R. Khavandi, R. Ghasemzadeh, J. Alloys Compd. 520 (2012) 164-169.

8) O. Bayat, A.R. Khavandi, R. Ghasemzadeh, Russ. J. Non-Ferr. Met. 53 (2012) 476-482.

9) R.O. Suzuki, H. Kitagawa, Electrochemistry 73 (2005) 724-729.

10) A. Verma, R.K. Sidhu, S. Mahajan, O.P. Oandey, J. Mater. Sci. Lett. 15 (1996) 2088-2090.

11) K. Fujiwara, T. Oishi, K. Ono, Metall. Trans. B 23 (1992) 415-421.

12) K. Ono, R. O. Suzuki, JOM 54 (2002) 59-61.

13) R. O. Suzuki, J. Phys. Chem. Solids 66 (2005) 461-465.

14) R. O. Suzuki, K. Ono, K. Terabuma, Metall. Mater. Trans. B 34 (2003) 287-295.

15) R. O. Suzuki, S. Fukui, Mater. Trans. 45 (2004) 1665-1671.

16) I. Ueda, M. Baba, T. Kikuchi, R.O. Suzuki, Electrochim. Acta 100 (2013) 269-274.

17) R.F. Descallar-Arriesgado, N. Kobayashi, T. Kikuchi, R.O. Suzuki, Electrochim. Acta 56 (2011) 8422-8429.

18) R. Enmei, T. Kikuchi, R.O. Suzuki, Electrochim. Acta 100 (2013) 257-260.

19) S. Osaki, H. Sakai, R.O. Suzuki, J. Electrochem. Soc. 157 (2010) E117-E121.

20) K. Otake, H. Kinoshita, T. Kikuchi, R.O. Suzuki, Electrochim. Acta 100 (2013) 293-299.

21) K. Otake, H. Kinoshita, T. Kikuchi, R.O. Suzuki, J. Phys. Conf. Ser. 379 (2012) 012038.

22) G.Z. Chen, D. J. Fray, W. W. Farthing, Nature 407 (2000) 361-364.

23) G.Z. Chen, D. J. Fray, J. Electrochem. Soc. 149 (2002) E455-E467.

24) R.L. Centeno-Sánchez, D. J. Fray, G.Z. Chen, J. Mater. Sci. 42 (2007) 7494-7501.

25) D.T.L. Alexander, C. Schwandt, D. J. Fray, Electrochim. Acta 56 (2011) 3286-3295.

26) P.K. Tripathy, M. Gauthier, D. J. Fray, Metall. Mater. Trans. B 38 (2007) 893-900.

27) A. Cox, D. J. Fray, J. Appl. Electrochem. 38 (2008) 1401-1407.

28) E. Gordo, G.Z. Chen, D. J. Fray, Electrochim. Acta 49 (2004) 2195-2208.

29) K.S. Mohandas, D. J. Fray, Metall. Mater. Trans. B 40 (2009) 685-699.

30) A.M. Abdelkader, D. J. Fray, Electrochim. Acta 64 (2012) 10-16.

31) R. Barnett, K.T. Kilby, D. J. Fray, Metall. Mater. Trans. B 40 (2009) 150-157.

32) A.M. Abdelkader, D. J. Fray, Electrochim. Acta 55 (2010) 2924-2931.

33) D.J.S. Hyslop, A.M. Abdelkader, A. Cox, D. J. Fray, Acta Mater. 58 (2010) 3124-3130.

34) A.M. Abdelkader, D. J. Fray, J. Eur. Ceram. Soc. 32 (2012) 4481-4487.

35) S. Wang, Y. Li, J. Electroanal. Chem. 571 (2004) 37-42.

36) K. Dring. R. Dashwood, D. Inman, J. Electrochem. Soc. 152 (2005) E104-E113.

37) L.I.U. Meifeng, L.U. Shigang, S. Kan, L.I. Guoxun, Rare Metals 26 (2007) 547-551. 
38) K. Dring, R. Dashwood, D. Inman, J. Electrochem. Soc. 152 (2005) D184-D190.

39) R. Bhagat, M. Jackson, D. Inman, R. Dashwood, J. Electrochem. Soc. 156 (2009) E1-E7.

40) R. Bhagat, M. Jackson, D. Inman, R. Dashwood, J. Electrochem. Soc. 155 (2008) E63-E69.

41) B. Jackson, M. Jackson, D. Dye, D. Inman, R. Dashwood, J. Electrochem. Soc. 155 (2008) E171-E177.

42) M. Panigrashi, A. Iizuka, E. Shibata, T. Nakamura, J. Alloys Compd. 550 (2012) 545-552.

43) M. Panigrashi, E. Shibata, A. Iizuka T. Nakamura, Electrochim. Acta 93 (2013) 143-151.

44) T. Kikuchi, M. Yoshida, Y. Taguchi, H. Habazaki, R.O. Suzuki, J. Alloys Compd. 586 (2014) 148-154.

45) H. Habazaki, K. Takahiro, S. Yamaguchi, K. Shimizu, P. Skeldon, G.E. Thompson, G.C. Wood, Philos. Mag. A 78 (1998) 171.

46) H. Habazaki, K. Shimizu, S. Nagata, P. Skeldon, G.E. Thompson, G.C. Wood, Corr. Sci. 44 (2002) 1047-1055.

47) H. Habazaki, M. Uozumi, H. Konno, K. Shimizu, S. Nagata, K. Asami, K. Matsumoto, K. Takayama, Y. Oda, P. Skeldon, G.E. Thompson, Electrochim. Acta 48 (2003) 3257-3266.

48) H. Habazaki, M. Uozumi, H. Konno, S. Nagata, K. Shimizu, Surf. Coat. Technol. 169-170 (2003) 151-154.

49) H. Habazaki, K. Shimizu, S. Nagata, K. Asami, K. Takayama, Y. Oda, P. Skeldon, G.E. Thompson, Thin Solid Films 479 (2005) 144-151.

50) H. Habazaki, M. Uozumi, H. Konno, K. Shimizu, S. Nagata, K. Takayama, Y. Oda, P. Skeldon, G.E. Thompson, J. Electrochem. Soc 152 (2005) B263-B270.

51) H. Habazaki, H. Konno, K. Shimizu, J. Surf. Fin. Soc. Jpn. 54 (2003) 456-461.

52) G. Cappelletti, C. Ricci, S. Ardizzone, C. Parola, A. Anedda, J. Phys. Chem. C 109 (2005) 4448-4454.

53) K.T. Jacob, S. Gupta, JOM 54 (2009) 56-59.

54) J. Mohanty, K.G. Mishra, R.K. Paramguru, B.K. Mishra, Metall. Mater. Trans. B 43 (2012) 513-518.

55) Y. Mizusaki, K. Matsumoto, Japan patent (1993) No. 5-263101.

56) S.P. Albu, P. Schmuki, Electrochim. Acta 91 (2012) 90-95. 


\section{Captions}

Table 1 Phase, oxygen content, and BET specific surface area of the as-received and reduced nano-particles obtained by reduction with a calcium reductant.

Fig. 1 X-ray diffraction patterns of the $\mathrm{TiO}_{2}$ a) micro-, b) submicron-, and c) nano-particles as the starting materials for reduction with a calcium reductant.

Fig. 2 X-ray diffraction patterns of the reduced $\mathrm{TiO}_{2}$ a) micro-, b) submicron-, and c) nano-particles after reduction with a calcium reductant in $\mathrm{CaCl}_{2}$ molten salt at $1173 \mathrm{~K}$ for $15 \mathrm{~min}$. The amount of calcium reductant used was $150 \%$ the theoretical amount required for complete $\mathrm{TiO}_{2}$ reduction (50\% excess calcium).

Fig. 3 X-ray diffraction patterns of the reduced $\mathrm{TiO}_{2}$ a) micro-, b) submicron-, and c) nano-particles after reduction for $30 \mathrm{~min}$.

Fig. 4 Change in the residual oxygen content, $\mathrm{C}_{\mathrm{o}}$, of reduced micro-, submicron-, and nano-particles with reduction time, t: for a) $60 \mathrm{~min}$ and b) $360 \mathrm{~min}$.

Fig. 5 Surface appearances of the nano-particles submitted to reduction for a) $60 \mathrm{~min}$ and b) $360 \mathrm{~min}$.

Fig. 6 SEM images of a) $\mathrm{TiO}_{2}$ micro-particles used as the starting materials and the materials reduced by a calcium reductant for b) $15 \mathrm{~min}$, c) $120 \mathrm{~min}$, and d) $360 \mathrm{~min}$.

Fig. 7 SEM images of a) $\mathrm{TiO}_{2}$ submicron-particles used as the starting materials and the materials reduced by a calcium reductant for b) $15 \mathrm{~min}$, c) $120 \mathrm{~min}$, and d) $360 \mathrm{~min}$.

Fig. 8 SEM images of a) $\mathrm{TiO}_{2}$ nano-particles used as the starting materials and the materials reduced by a calcium reductant for b) $15 \mathrm{~min}$, c) $120 \mathrm{~min}$, and d) $360 \mathrm{~min}$.

Fig. 9 Schematic model illustrating the reduction behaviors of the a) $\mathrm{TiO}_{2}$ micro- and b) nano-particles. 
Table 1

\begin{tabular}{llcc}
\hline Reduction time & Phase & Oxygen content & BET specific surface area \\
\hline 0 min (as received) & $\mathrm{TiO}_{2}$ & $40.1 \mathrm{wt}^{2} \%$ & $120.3 \mathrm{~m}^{2} \mathrm{~g}^{-1}$ \\
$60 \mathrm{~min}$ & $\mathrm{Ti}$ & $0.42 \mathrm{wt} \%$ & $1.794 \mathrm{~m}^{2} \mathrm{~g}^{-1}$ \\
$360 \mathrm{~min}$ & $\mathrm{Ti}$ & $0.23 \mathrm{wt} \%$ & $0.1554 \mathrm{~m}^{2} \mathrm{~g}^{-1}$ \\
& & & \\
\hline
\end{tabular}




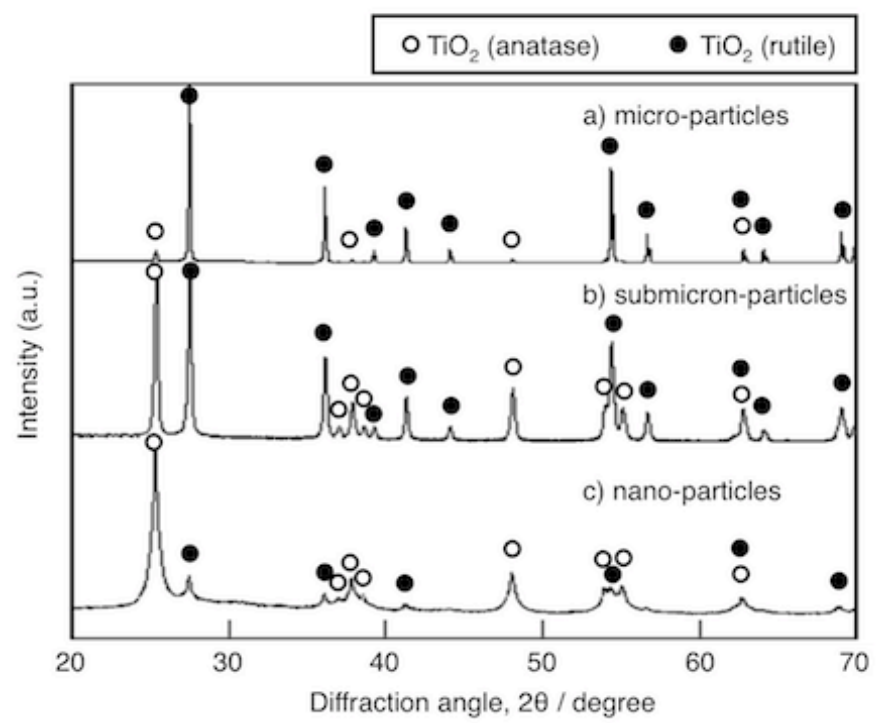

Fig. 1 


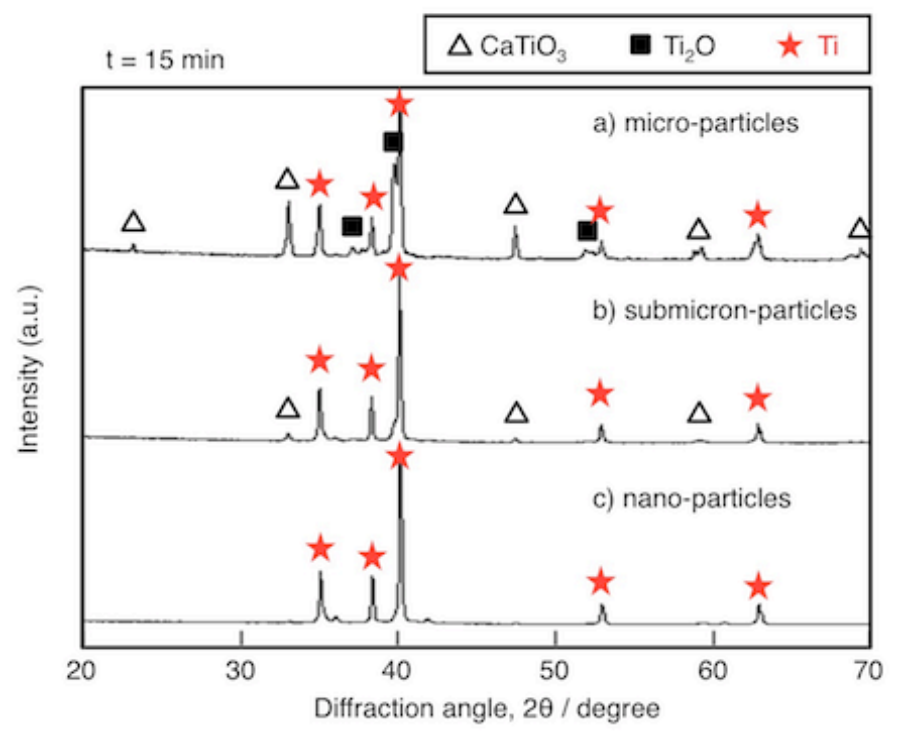

Fig. 2 


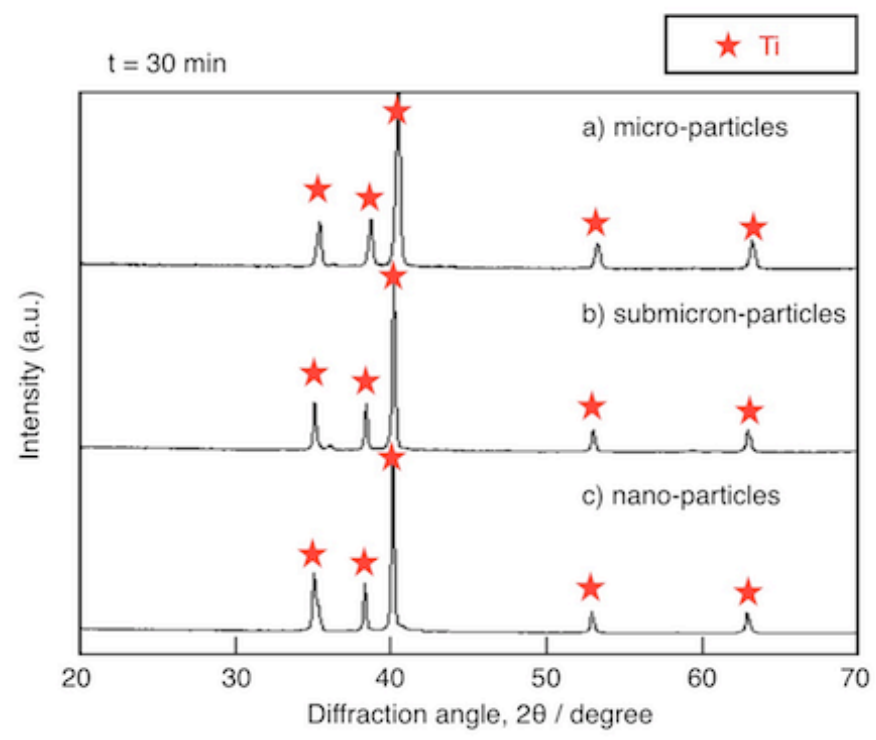

Fig. 3 

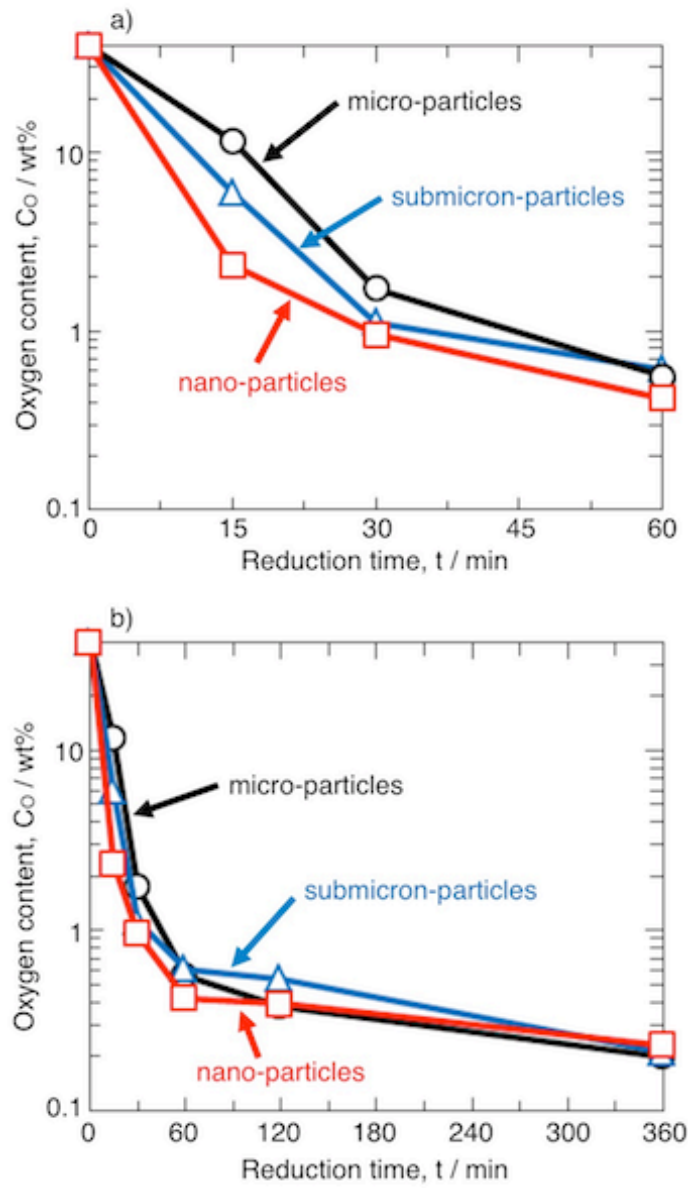

Fig. 4 

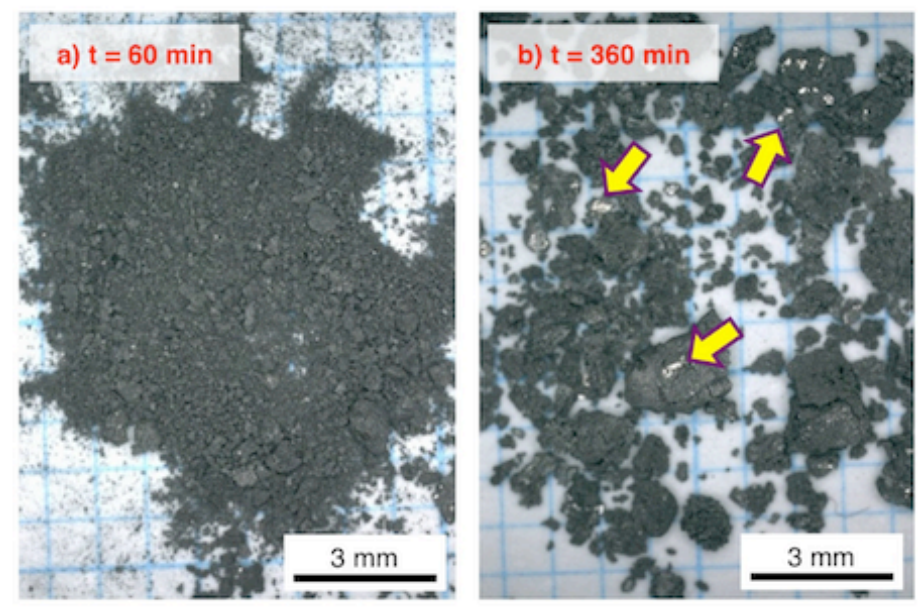

Fig. 5 


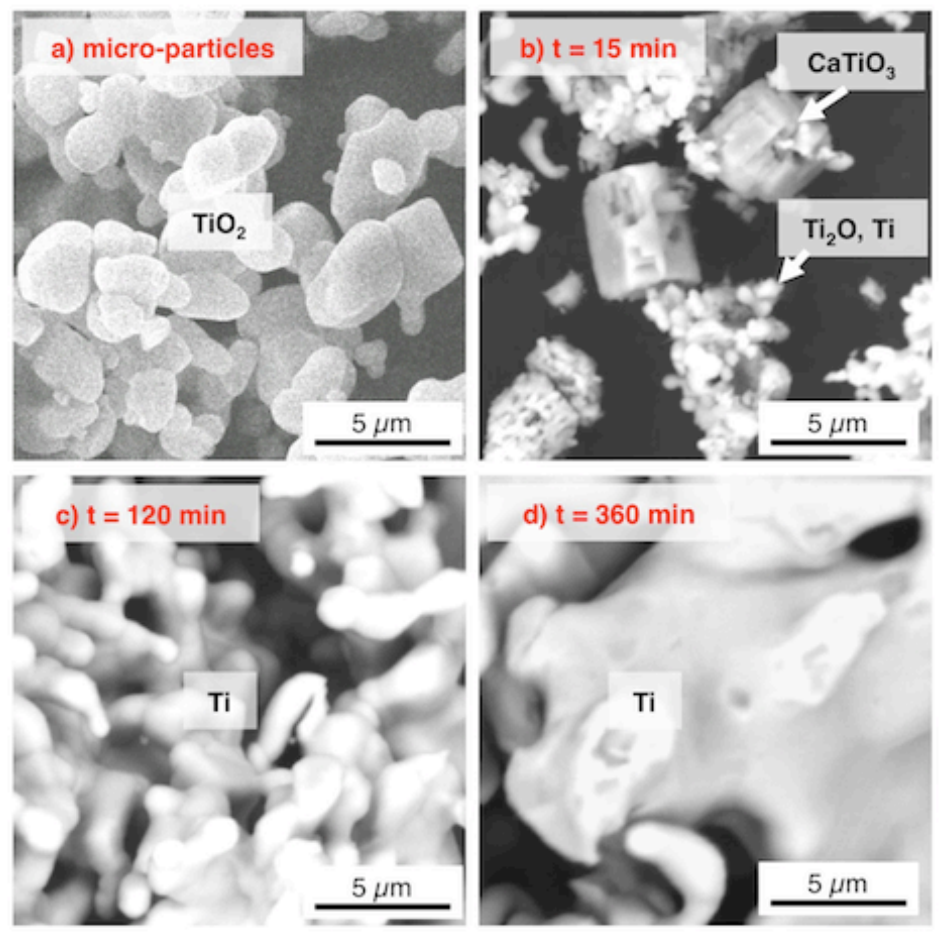

Fig. 6 

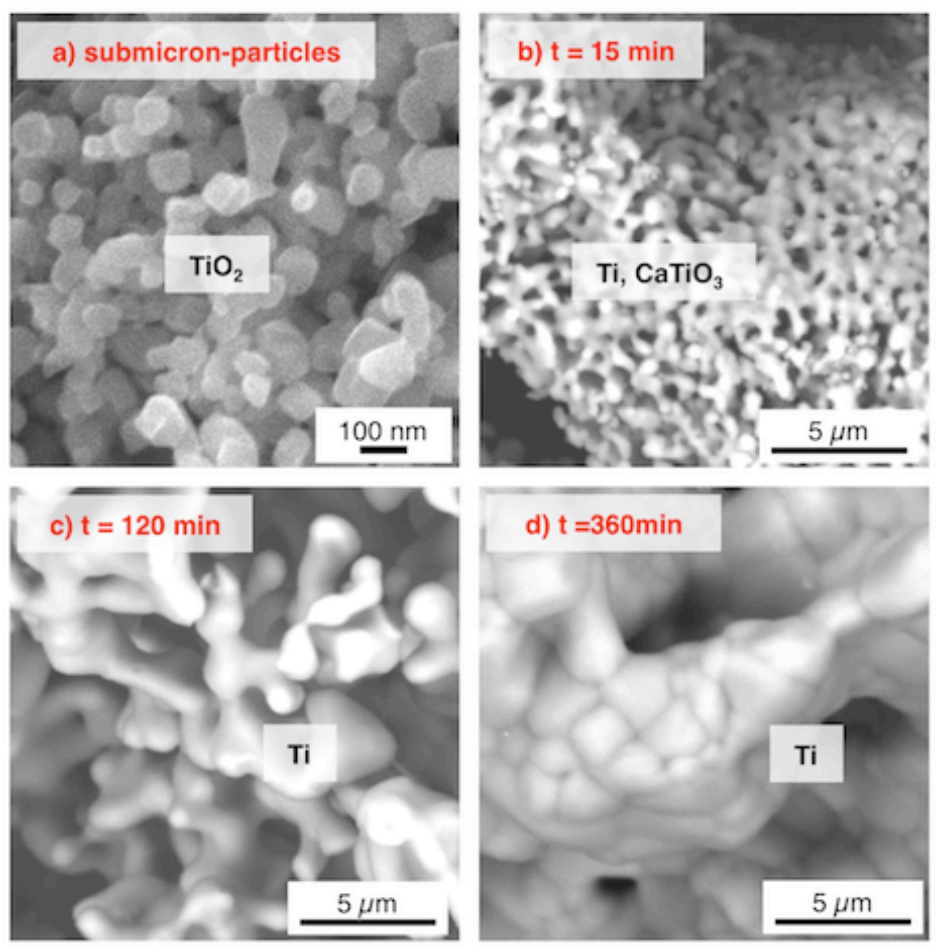

Fig. 7 

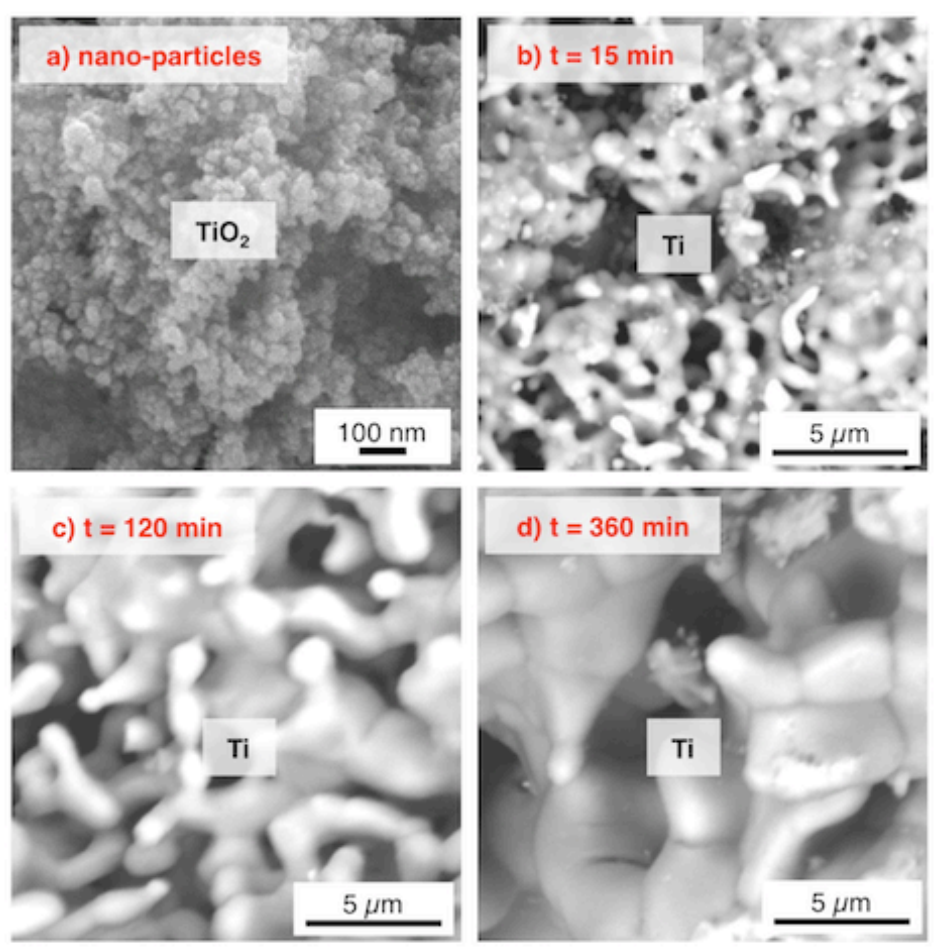

Fig. 8 
a) $\mathrm{TiO}_{2}$ micro-particle reduction

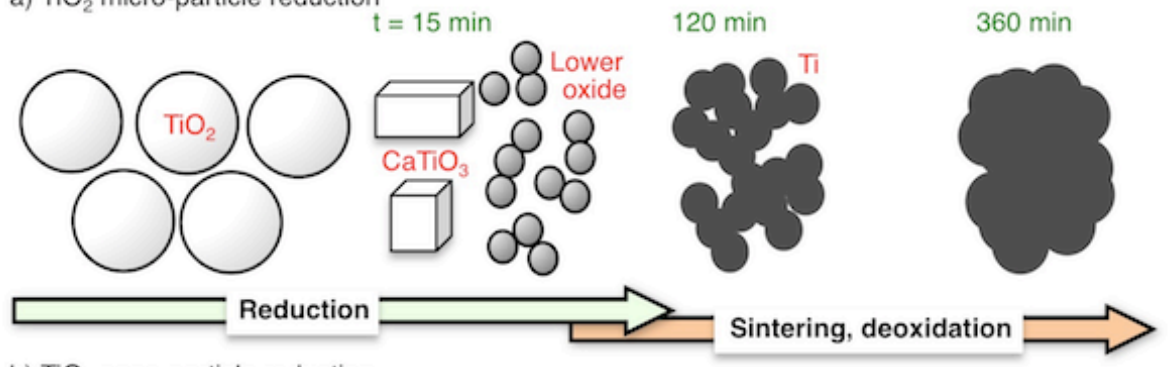

b) $\mathrm{TiO}_{2}$ nano-particle reduction

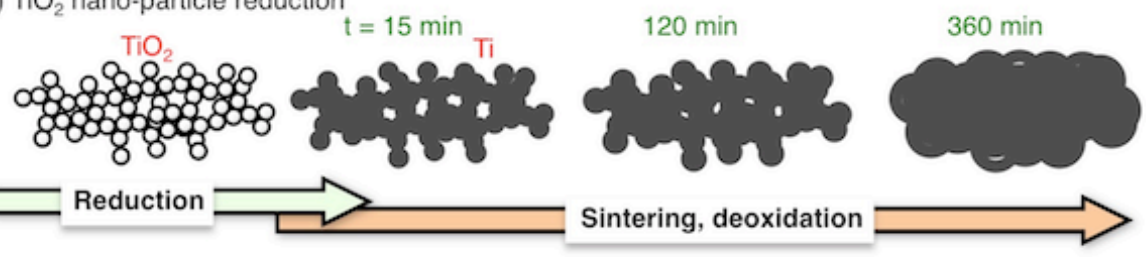

Fig. 9 